\title{
TESES DE DOUTORADO E DISSERTAÇÕES DE MESTRADO DEFENDI DAS
}

\author{
(Novembro de 2008 a Maio de 2009)
}

\section{Teses de Doutorado}

\section{O novo tempo do cerrado: expansão dos fronts agrícolas e controle do sistema de armazenamento de grãos}

\section{Samuel Frederico}

\section{Orientador: Prof. Dr. Francisco Capuano} Scarlato

O presente estudo analisa, numa perspectiva mais ampla, as principais características do novo tempo do Cerrado. Estas estão intimamente relacionadas à propagação dos fronts agrícolas, ou seja, da agricultura moderna, a partir da década de 1970. Esta agricultura, realizada de maneira intensiva e em larga escala, introduziu nos cerrados brasileiros um novo tempo, ao implantar sistemas técnicos extremamente funcionais à produção agrícola moderna, permitindo às grandes empresas um maior domínio da produção. Dentre os sistemas técnicos controlados pelas empresas, o sistema de armazenamento se destaca, ao configurar-se como um dos principais elos logísticos dos diversos circuitos espaciais produtivos agrícolas. Os silos permitem cadenciar a circulação dos grãos no tempo e no espaço, sendo imprescindíveis desde a produção (strictu sensu), até os estágios finais de exportação e consumo. Nos fronts agrícolas, o controle do sistema de armazenamento se torna ainda mais estratégico, por se tratar da principal região produtora de grãos do país, pela grande distância com relação aos portos exportadores e regiões consumidoras e pela precariedade dos sistemas de transporte. Esse contexto torna a posse do sistema de armazenamento um elemento chave para o controle da produção. É por isso que nas principais regiões produtoras a posse dos sistemas de armazenamento é ainda mais seletiva, sendo controlada pelas grandes firmas processadoras e exportadoras de grãos, tornando os produtores e o Estado subservientes à política das empresas. Portanto, esta pesquisa analisa de maneira mais estrita como o domínio do sistema de armazenamento de grãos confere às empresas um maior poder de regulação da produção agrícola e um uso privilegiado do território.

\section{A geopolítica da rede e a governança global de internet a partir da cúpula mundial sobre a sociedade da informação}

\section{Michele Tancman Candido da Silva}

Orientador: Prof. Dr. José William Vesentini

São inúmeros os países que debatem a supervisão política da Internet. Do ponto de vista geográfico, a atual supervisão, pela ICANN, reflete a centralização do poder e do controle mantido por um único país, os EUA. 
Este fato fragmenta os demais Estados Nacionais que buscam formar uma Governança de Internet multilateral. Uma das questões centrais que buscamos desvendar em nosso trabalho é identificar se há possibilidade de se estabelecer uma Governança Global de Internet capaz de atuar no modelo multistakeholder, ou multilateral, cuja responsabilidade governamental atua com atores da sociedade para um pacto global de Internet onde as correlações de forças se alteram de forma democrática, eqüitativa e equilibrada, igualitária com objetivo de atender as demandas da sociedade global. No intuito de verificar a constituição do modelo de governança da Internet brasileira investigamos a história da implantação da Internet no Brasil, desde instalação das redes acadêmicas não comerciais, no final dos anos 80, à formação do marco regulatório com a criação do Governo Eletrônico em 1995. Até o momento as questões geopolíticas que envolvem a Governança de Internet, a partir de um sistema internacional, demonstram que as propostas atendem a múltiplos interesses e que podem levar a conflitos, porque são de difíceis consensos e também por ser assuntos relacionados à privacidade, padrões de abertura, acesso e conectividade, multilingüismo, spam, acesso ao conhecimento, liberdade de expressão e os Direitos e Deveres da Internet. A metodologia empregada neste trabalho se consubstanciou na elaboração de pesquisas, levantamentos bibliográficos, entrevistas e trabalhos de campo que renderam em torno de 60 horas de gravação. Buscamos ainda compreender e efetuar uma reflexão dos conceitos aplicados à Governança, enfatizando que uma Governança mundial é um conceito políticoestratégico que revela grandes e difíceis questões que afetam as economias nacionais e a atual ordem mundial, com desdobramentos que irão obviamente provocar mudanças no território dessas economias. A intervenção regulatória é cada vez maior no desenvolvimento das redes de comunicação que têm alcance global. Na geografia, o termo governança quando adicionado às categorias espaço e território remetem as questões e conteúdos relacionados à soberania, à geopolítica, à regulação (ordenamento) e ao controle jurídico da autoridade política estabelecida ou em exercício, que dizem respeito ao poder para ou ao poder sobre. A transição da Governança unilateral da Internet para uma Governança de Internet multilateral, baseada no modelo multistakeholder, cujo anseio visa estabelecer um novo modelo de Governança formulado por múltiplos atores, de modo transparente e democrático, assentada em princípios de cooperação concebidos de forma compartilhada, teve início a partir da Resolução 56/183 da ONU, em que todos os organismos das Nações Unidas foram convocados para contribuir para a formação da Cúpula Mundial sobre a Sociedade de Informação (CMSI), juntamente com representações da sociedade civil, de organizações nãogovernamentais e de organizações intergovernamentais. Em seguida a instituição do Internet Fórum Global (IGF). Este novo modelo vem sendo constituído como uma prerrogativa do exercício soberano dos Estados Nacionais, e está em fase de consolidação.

\section{As abordagens sistêmica e do equilíbrio dinâmico na análise da fragilidade ambiental do litoral do Estado de São Paulo: contribuição à geomorfologia das planícies costeiras}

Marisa de Souto Matos Fierz

Orientador: Prof. Dr. Jurandyr Luciano Sanches Ross

A presente pesquisa tem como objetivo principal avaliar, por meio da abordagem sistêmica e do equilíbrio dinâmico, as 
Teses de Doutorado e Dissertações de Mestrado Defendidas

(Novembro de 2008 a Maio de 2009), pp. 195 - 203

diferenças de configurações geológicas e geomorfológicas e de fragilidade nos variados compartimentos geomorfológicos ao longo das planícies costeiras na enseada da Fortaleza, em Ubatuba, litoral norte de São Paulo e região de Peruíbe-Itanhaém, litoral centro-sul de São Paulo. Essas diferenças de configurações morfológicas são resultantes de processos pretéritos e do arcabouço geológico que sustentam as formas manifestadas na paisagem, moldadas pelos processos que atuam como agentes modeladores e de manutenção do equilíbrio dinâmico dessas formas. O equilíbrio dinâmico, nos moldes ecogeográficos de Tricart (1977), é mantido pela cobertura vegetal que pode manter constantes os processos de morfogênese e pedogênese ao longo da planície costeira que constituída de material friável, areias finas a muito finas que lhes conferem, a princípio, um caráter de fragilidade intrínseca. O equilíbrio dinâmico nos moldes geomorfológicos de Hack $(1960,1965)$ é mantido pela variação da resistência dos materiais que compõem o relevo, sustentando as formas. Essas duas abordagens auxiliaram na determinação da fragilidade ambiental, que é identificada e representada, sobretudo, pelas variações de resistência entre os diversos compartimentos ou subsistemas geomorfológicos mapeados ao longo da planície. Entretanto, em alguns trechos da planície costeira, sobretudo no litoral sul, onde o solo do tipo espodossolo apresenta horizonte $B$ espódico também denominado, nesta tese, de fragipã (?), cuja principal característica é de caráter endurecido pela composição de ácidos húmicos e fúlvicos, retidos ali pelo processo de podzolização. Nestes trechos, os testes de resistência resultaram em poucos impactos de penetração ou nulos. O horizonte $B$ espódico rígido, destarte a classificação da fragilidade ambiental obteve diversidades influenciadas pelas características desses trechos de espodossolos e por apresentarem interferências diretas nos processos de mudanças dos níveis topográficos.

\section{A especialização do lugar: São J osé dos Campos como centro da tecnologia aeroespacial no País}

\author{
Adriane Aparecida Moreira de Souza
}

Orientador: Prof. Dr. Wanderley Messias da Costa

Esta tese tem o objetivo de analisar o município de São José dos Campos sob a perspectiva de um novo espaço da produção industrial. Na cidade, os processos de inovação tecnológica cumprem a lógica produtiva estabelecida em meados do século $X X$, quando o conhecimento científico foi com mais intensidade incorporado aos processos de produção. Porém, foi em meio à Segunda Guerra Mundial que, a exemplo de outros países, o governo brasileiro inicia um projeto de criação de uma base científica e tecnológica com vistas no desenvolvimento da indústria bélica e de setores correlatos, escolhendo o município para concretizá-lo. Nesta tese, o município é reconhecido como o centro da tecnologia aeroespacial brasileira, cujo núcleo composto pelo Instituto Tecnológico de Aeronáutica (ITA), pelo Comando-Geral de Tecnologia Aeroespacial (CTA), pelo Instituto Nacional de Pesquisas Espaciais (INPE) e pela Empresa Brasileira de Aeronáutica S.A (Embraer) reproduz características semelhantes aos principais centros de inovação tecnológica do mundo. Por meio dessas instituições, o município estabelece interações com diversas localidades do País e com outros países do continente americano, da Ásia, da Europa e da África. Neste contexto de interações, verificase a demanda pelos cursos de pós-graduação oferecidos pelo ITA e pelo INPE por parte de profissionais provenientes de outras regiões do País e de outros países para o 
aperfeiçoamento em áreas correspondentes à Engenharia Aeronáutica ou às Ciências Espaciais, bem como o desenvolvimento de projetos, por essas instituições, em parceria com instituições estrangeiras. É ainda por meio do ITA e do INPE que é preparada grande parte da mão-de-obra qualificada que atende o setor, numa evidentedemonstração de sinergia entre essas instituições e empresas locais. A quantificação de empresas do setor aeroespacial mostra que o município abriga - maior número de empresas produtoras dos insumos utilizados no processo de fabricação de aeronaves em todo o País. Quando considerados os indicadores de ciência, tecnologia e inovação tecnológica, verifica-se que o município, representado pelo ITA e pelo INPE, está entre os de maior produção científica do estado de São Paulo, e que, apesar do reduzido número de depósitos de registro de patentes, o setor vem apresentando esforços neste sentido, demonstrando um aumento da capacidade de transformar os avanços científicos em inovações para o setor.

\section{Campesinato e os faxinais do Paraná: as terras de uso comum}

\section{Luis Almeida Tavares}

Orientador: Prof. Dr. Ariovaldo Umbelino de

A prática de terras de uso comum desde tempos imemoriais, nas suas mais diversas formas, foi ou ainda é praticada em diversas partes do mundo, como na França (Vaine Pâtre, Biens Communaux), Itália (Della Comurione, Le Terre Del Compascuo), Angola, Colômbia, Portugal (Baldios), Espanha (Baldios e Montes Veciñais en Mam Común), Alemanha, Inglaterra, Ucrânia, Polônia, Brasil, entre outros países. No Brasil, as terras de uso comum e seus recursos naturais são apropriados por uma fração do campesinato. O uso dessas terras envolve elementos de identidade, indissociáveis do território ocupado, e regras de apropriação, que se expressam em diversas formas e denominações, como 'Terras de Preto', 'Terras de Santo', 'Terras dos Índios', 'Terras de Herança', 'Terras Soltas', 'Fundo de Pasto' e 'Faxinais'. Entendendo que até o presente momento, existe uma lacuna na Geografia Agrária Brasileira quanto à elaboração de uma pesquisa que aprofunde a análise sobre o campesinato, pautei como objetivo central desse trabalho a interpretação da trajetória histórica dessa fração do campesinato e seu território. Para isso, compreendo abstratamente que o campesinato, por meio de lutas, constitui-se como uma classe social, para si, e que, como sujeitos políticos, para se sustentarem no modo capitalista de produção, travam uma luta de classe. Para compreender o uso das terras de uso comum e de seus recursos naturais por essa fração do campesinato brasileiro e, mais especificamente, paranaense, fez-se necessário resgatar como se davam essas práticas na Espanha e Portugal, assim como suas diversas formas e respectivas variantes de posse e propriedade da terra no Brasil. Considerando-se que a gênese dos faxinais do Paraná se deu por meio de uma aliança, construída nas grandes fazendas dos Campos Gerais do Paraná entre uma parcela de índios escravos e negros africanos escravos fugidos, a qual se concretizou nas matas mistas de Araucárias e se consolidou com a contribuição de uma fração de camponeses poloneses e de imigrantes ucranianos, que conseguiram escapar do genocídio da Guerra do Contestado. Na contemporaneidade, a formação social do faxinal tem diversas definições, tanto do ponto de vista de pesquisadores do Estado, quanto dos camponeses faxinalenses, que englobam seu tripé de sustentação: terras de uso comum no criadouro comum ou comunitário, cercas das terras de uso comum 
Teses de Doutorado e Dissertações de Mestrado Defendidas

(Novembro de 2008 a Maio de 2009), pp. 195 - 203

do criadouro comum ou comunitário e terras agrícolas ou terras de planta. As práticas sociais comuns e religiosas são o que consolidam o modo de vida dos camponeses faxinalenses, mesmo enfrentando conflitos sociais e ambientais. Os resultados dessa pesquisa confirmam a luta e a resistência dos camponeses faxinalenses para se manterem enquanto classe para si e a certeza da manutenção da formação social do faxinal ou da sua expansão por meio da reconquista de espaços da fração do território comunitário camponês faxinalense expropriado pelo desenvolvimento do modo capitalista de produção no campo paranaense.

\section{Dissertações de Mestrado}

\section{A dialética da construção destrutiva na consagração do patrimônio mundial: o caso de Diamantina (MG)}

\section{Everaldo Batista da Costa}

Orientador: Prof. Dr. Francisco Capuano Scarlato

Esta Dissertação cuja elaboração está focada em uma perspectiva históricodialética tem por objetivo analisar o processo de consagração do Patrimônio Cultural da Humanidade [UNESCO] e o Programa Monumenta [Municípios / Governo Federal / BID] a fim de identificar, em Diamantina cidade histórica do sertão mineiro através de uma análise crítica, como o par dialético preservação / mercantilização produz o espaço urbano em tela e como transforma a realidade e o imaginário do residente. Denominamos essa contradição como dialética da construção destrutiva, que envolve os bens culturais do mundo, na contemporaneidade. Esta dialética estabelece-se no próprio percurso de consagração do Patrimônio Mundial, quando temos, por um lado, a UNESCO, que luta pela preservação inconteste dos bens culturais e naturais do mundo, em contraposição à tendência contemporânea de mercantilização, banalização e destruição dos espaços da história, da memória, da cultura, da natureza e da vida, quando da implantação de um turismo negligente com a sociedade e com o lugar. Dialética da construção destrutiva que rebate sobre o espaço urbano, a cidade histórica viva enquanto totalidade, ao ser reconhecida, simultaneamente, como símbolo de cultura e de mercadoria. Assumimos uma postura crítica frente a simultaneidade da preservação e da mercantilização do patrimônio um processo contraditório dada a preponderância do caráter estético, fetichista, classista e de cenarização na apropriação das cidades históricas e na refuncionalização dos bens culturais, em detrimento ao seu valor de uso civilizatório. Analisamos esta realidade que se evidencia, incipientemente, em Diamantina (Patrimônio Mundial e mercadoria global), sobretudo, com a conquista da chancela da UNESCO e com a implantação do polêmico Programa Monumenta. Veremos que a cidade histórica, ao ser tomada pela indústria cultural por via de um turismo descompromissado com a sociedade e com o lugar, é destituída de sua particularidade no fortalecimento do sentimento de pertencimento ao lugar e na edificação da cidadania. Ante ao frénésie pela Lista do Patrimônio Mundial, que esboça a lógica mercantil que envolve os bens culturais, na atualidade, urge a implementação da gestão participativa dos lugares do patrimônio e o enfoque no planejamento da cidade histórica enquanto totalidade, não focado nos limites do núcleo tombado. Por fim, é no contexto da dialética entre o uso e a troca que se dá na apropriação do espaço urbano, e entre a preservação e a mercantilização do 
patrimônio cultural que direcionamos esta pesquisa, que identifica a fragmentação articulada propiciada pela dialética da construção destrutiva que impactua o território urbano de Diamantina, no sertão de Minas Gerais.

\section{A integração precária e a resistência indígena na periferia da metróple}

Camila Salles de Faria

Orientadora: Profa. Dra. Ana Fani Alessandri Carlos

Trata-se de um debate sobre os processos de mudanças ocorridos nas aldeias indígenas Guarani Mbya do Jaraguá, localizadas na zona noroeste do município de São Paulo. Estes processos são decorrentes dos conflitos de duas diferentes lógicas que coexistem no mesmo espaço, em uma porção da periferia da metrópole. É o embate entre a lógica capitalista, hegemônica na metrópole, que produz seu espaço, a propriedade privada, que tenta moldar o espaço da comunidade indígena e a lógica indígena, oposta a acumulação. Neste sentido, obrigaram os indígenas à aceitação de um espaço produzido pelo Estado, Terra Indígena (T.I.), e limitado pelo processo de periferização da metrópole. Porém, não sem reação, já que os indígenas ocupam outras áreas, e formam novas aldeias. Assim, este processo pode ser lido através da contradição integração/ desintegração deste povo no que se pode chamar de universo urbano. Porém, este é um processo contraditório que não se realiza de forma integral, revelando sua negatividade através de outro momento, a resistência. A resistência suposta pelo uso e apropriação que a comunidade exerce através de suas relações sociais fundamentadas por sua cultura é que vai produzir um espaço diferenciado dentro da metrópole paulistana, um espaço considerado de resistência.

\section{Uma abordagem geográfica do turismo em Porto Seguro}

\author{
Clébia Rodrigues de Carvalho
}

Orientadora: Profa. Dra. Sueli Ângelo Furlan

Este estudo apresenta os vários processos de ocupação socioeconômica do extremo sul da Bahia e principalmente as implicações socioambientais decorrentes do turismo. Com a abertura da BR 101 em meados da década de 1950, e seu asfaltamento no início dos anos 1970, o turismo se desenvolveu e se impôs como atividade econômica principal da região, devido aos seus inúmeros recursos turísticos. As novas formas de (re)ordenar o espaço físico, decorre de intervenção do Estado em paralelo com o Prodetur - NE, a partir dos anos 1990, quando o turismo estaria em sua fase de saturação. Dessa forma, o Programa de Desenvolvimento do Turismo no Nordeste, atinge Porto Seguro e seus arredores, visando ampliação e/ou modernização de infra-estrutura turística. Este acelerado crescimento urbano em Porto Seguro, não se fez em conjunto com nenhum tipo de planejamento adequado, gerando, assim, uma ocupação desordenada do espaço urbano. A cidade cresceu, mas sem um adequado acompanhamento da infraestrutura básica como o sistema de abastecimento de água, fornecimento de energia elétrica e calçamento das ruas, além, da ocupação imobiliária, a alteração e descaracterização da paisagem, o deslocamento das populações, o aumento demográfico sazonal, e o conseqüente aumento na produção de esgoto e lixo, etc. Diante desse contexto, e considerando que o turismo desponta, nos últimos anos, como importante fenômeno social e fator de 
Teses de Doutorado e Dissertações de Mestrado Defendidas

(Novembro de 2008 a Maio de 2009), pp. 195 - 203

desenvolvimento econômico, através da revalorização dos recursos locais disponíveis e a conseqüente dinamização da economia local e regional, o poder público tem incentivado o desenvolvimento da atividade turística elegendo-a como uma saída para o crescimento local. No entanto, as políticas de turismo nacionais precisam ser repensadas em função da própria dinâmica da atividade, procurando assegurar a sustentabilidade com um modelo de desenvolvimento turístico planejado no sentido de manter a sua permanência a longo prazo, integrando as populações locais e a minimização ou, na melhor das hipóteses, a eliminação das implicações socioambientais e culturais.

\section{Formam-se favelas e ganham importância no cenário urbano São Paulo: Heliópolis e Paraisópolis}

\section{Nelson Antonio Alessi}

Orientador: Prof. Dr. José William Vesentini

Este trabalho tem a finalidade de empreender uma reflexão crítica a respeito do mundo da formação de favelas que encontramos no espaço urbano da Cidade de São Paulo. Abordamos ainda, mesmo que de passagem, os cortiços, pelo fato de terem uma semelhança com a favela em seu aspecto fisionômico, porque ambos constituem moradias precárias onde se encontram famílias de baixa renda. Para isso destacamos através de tabelas, fotos, pesquisa bibliográfica e pesquisa de campo realizada em ambientes de favela e cortiço, determinadas fundamentais a cada ambiente em questão. E é a partir da atividade transformadora dos objetos em questão que podemos não só mostrar como se iniciaram, mas a realidade atual, trazendo ao leitor amostra de ocupação, estruturação e incorporação de um novo espaço urbano fazendo parte da Cidade. O tema abordado neste trabalho tem a intenção de mostrar a implantação da favela provocando um grande impacto ambiental e social. Procura ainda mostrar as mudanças nas edificações através de seus diferentes projetos, a ocorrência de riscos no ambiente de favela, além de propor um intercâmbio entre as diversas disciplinas das ciências sociais. Destacam-se nos ambientes de favela um grande movimento circulatório de pessoas caracterizando uma densidade demográfica bastante acentuada, o que também é típico dos cortiços. Neste ambiente há uma verdadeira mini cidade, com comércio legal, negócios com mercadorias de procedência duvidosa, comércio de drogas, desenvolvimento de mercado imobiliário com forte aquecimento e principalmente o comércio informal em franco desenvolvimento nas diversas atividades. Mencionamos neste trabalho duas importantes amostras na Cidade de São Paulo, as quais são a Favela Heliópolis, a primeira em sua grandeza, e uma segunda amostra é a Favela Paraisópolis, tida como a segunda em grandeza. A implantação de Favela, ausente de um padrão de planejamento urbano, vem mostrar quão grande é a miséria na Cidade, quão problemática é a questão da moradia popular na maior metrópole brasileira, pois são ocupadas pela população de baixa renda, com fraco acesso aos bens e serviços da Cidade.

\section{O servidor de mapas da prefeitura de Taboão da Serra-SP: uma proposta de implantação}

Ricardo Saleimen Nader

Orientador: Prof. Dr. Reinaldo Paul Pérez Machado 
Foi estruturado um modelo de servidor de mapas, na plataforma MapGuide, capaz de disseminar eletrônicamente os dados geoespaciais gerados pela Prefeitura de Taboão da Serra SP. O projeto de servidor visou duas finalidades principais: implementar este tipo de tecnologia ao analista responsável pelo projeto, no âmbito da Prefeitura, e; tornar a dissertação um guia teóricometodológico introdutório a profissionais da Cartografia e Geociências, não especializados com este ramo das geotecnologias. O serviço de disseminação foi configurado para servir dados geoespaciais diretamente a navegadores de rede, servidores FTP e Sistemas de Informação Geográfica (SIG). Para estes últimos, foram utilizados recursos de acesso a dados localizados em servidores de mapas remotos, por meio dos serviços de Web Mapping Service (WMS) e Web Feature Service (WFS). Enquanto a disseminação em navegador de rede pode alcançar usuários não especializados com este campo das geotecnologias, a utilização de servidores FTP, serviços WMS e WFS remotos, favorece usuários técnicos das Geociências e Cartografia. Comparou-se as funcionalidades do MapGuide, a SIG de primeira e segunda geração, com funções topológicas completas. Concluiu-se que o servidor de mapas não possuía a mesma capacidade de análise espacial dos SIG topológicos.

\section{O componente social do plano Colômbia e a territorialidade da comunidade camponesa-indígena Awá do departamento do Putumayo (Colômbia)}

$$
\text { Camilo Alejandro Bustos Avila }
$$

Orientador: Prof. Dr. Júlio César Suzuki

Este trabalho sintetiza uma tentativa de explicação da complexidade socioespacial da relação dialética entre os camponeses- indígenas e o Estado, tomando o caso da comunidade camponesa-indígena Awá do Departamento do Putumayo, na região do piedemonte amazônico do sudoeste da Colômbia e que, desde sempre, tem sido área periférica no processo de conformação territorial do Estado-Nação colombiano. O desenvolvimento da pesquisa permitiu entrelaçar duas histórias, sendo, a primeira, da colonização do piedemonte do Putumayo por parte de comunidades camponesas e indígenas deslocadas das regiões adjacentes por efeito do processo de concentração da terra, as quais recriaram relações camponesas de produção no Putumayo baseadas na posse da terra e o cultivo da coca e, a segunda; a história do deslocamento das comunidades Awá de seu território ancestral no Departamento de Nariño até o Putumayo, processo em que se somaram ao resto do processo colonizador e perderam muitas das suas tradições ancestrais indígenas. A partir de meados da década de 1990, o Estado colombiano se embarca na tarefa de consolidar seu processo de institucionalização nas suas áreas periféricas (principalmente o Putumayo), mediante o combate à produção da coca, utilizando-se de estratégias de forte impacto para a vida das comunidades camponesas como a fumigação aérea e o controle militar. As comunidades reagem a esta iniciativa estatal com uma série de mobilizações em que reclamam seu direito a serem considerados como cidadãos e exigem a implantação do Desenvolvimento Alternativo. A resposta do Estado às mobilizações camponesas é a realização do Plano Colômbia, um gigantesco plano de combate à produção de coca mediante operativos militares para o confronto com as guerrilhas insurgentes, erradicação forçada dos cultivos de coca e imposição de estratégias de desenvolvimento alternativo, elaborado sob a influência dos Estados Unidos. Os impactos negativos deste plano e da incursão sistemática dos grupos paramilitares produziram um deslocamento 
Teses de Doutorado e Dissertações de Mestrado Defendidas

(Novembro de 2008 a Maio de 2009), pp. 195 - 203

em massa da população rural e o deterioro das condições de vida da população despejada da terra. Ante estes graves impactos, as comunidades camponesas como os Awá decidem retomar suas características ancestrais indígenas para assegurarem a propriedade da terra e outros benefícios consagrados na legislação, mas, neste processo vão se distanciando entre elas pela concorrência por benefícios estatais, e gerando processos de autosegregação. 
